\title{
BLENDED LEARNING \\ UMA ANÁLISE DO CONCEITO, CENÁRIO ATUAL E TENDÊNCIAS DE PESQUISA EM TESES E DISSERTAÇÕES BRASILEIRAS
}

\author{
BLENDED LEARNING \\ AN ANALYSIS OF THE CONCEPT, CURRENT SCENARIO AND RESEARCH TRENDS \\ IN BRAZILIAN THESIS AND DISSERTATIONS
}

\section{BLENDED LEARNING \\ UN ANÁLISIS DEL CONCEPTO, EL ESCENARIO ACTUAL Y LAS TENDENCIAS DE LA INVESTIGACIÓN EN TESIS Y DISSERTACIONES BRASILEÑAS}

Jiani Cardoso da Rozaㄹ; Adriana Moreira da Rocha Veiga²; Marcelo Pedroso da Roza ${ }^{3}$

\begin{abstract}
RESUMO
O Blended Learning é um modelo de educação formal que mescla a aprendizagem presencial com a virtual, em coexistência, valorizando os diferentes modos de interação, colaboração, envolvimento e promovendo a integração das tecnologias digitais na prática pedagógica dos professores. Neste artigo, com o objetivo de explorar como essa temática se apresenta no cenário educacional brasileiro, analisamos as dissertações e teses nacionais relacionadas a Blended Learning, no período de 2013 a 2017, disponibilizadas na Comissão de Aperfeiçoamento de Pessoal de Nível Superior e no Instituto Brasileiro de Informação em Ciência e Tecnologia. Assim, partimos de um estudo de revisão sistemática da literatura dessas produções, destacando o cenário atual e as compreensões em torno do assunto, e seguimos com a construção de uma síntese das pesquisas voltadas à Educação Superior e ao Ensino Médio. Como resultado, as pesquisas nos revelam um cenário crescente de estudos e experimentações com Blended Learning, elaboradas, geralmente, a partir de iniciativas individuais de professores, na intenção de potencializar a aprendizagem dos estudantes do século XXI.
\end{abstract}

PALAVRAS-CHAVE: Métodos de Ensino. Revisão de Literatura. Ensino Superior. Ensino Médio.

\section{ABSTRACT}

Blended Learning is a formal education program that mixes face-to-face and online learning, that values different modes of interaction, collaboration, involvement and promotes the integration of digital technologies into the pedagogical practice of teaches. With the objective of exploring how this issue is presented in the Brazilian educational scenario, we analyze dissertations and theses related to Blended Learning in Brasil, from 2013 to 2017. The. Data was available through Comissão de Aperfeiçoamento de Pessoal em Nível Superior and Instituto Brasileiro de Informação em Ciência e Tecnologia. We begin with a systematic literature review highlighting the

\footnotetext{
${ }^{1}$ Mestrado em Ciência da Computação - Pontifícia Universidade Católica do Rio Grande do Sul (PUCRS) - Porto Alegre, RS - Brasil. Doutoranda em Educação - Universidade Federal de Santa Maria (UFSM) - Santa Maria, RS Brasil. Professora do Ensino Básico, Técnico - Instituto Federal de Educação, Ciência e Tecnologia Farroupilha (IFFAR) - Alegrete, RS - Brasil. E-mail: jiani.roza@iffarroupilha.edu.br

${ }^{2}$ Doutora em Educação - Universidade Estadual de Campinas (UNICAMP) - Campinas, SP - Brasil. Professora Associada - Universidade Federal de Santa Maria (UFSM) - Camobi, Santa Maria, RS. Brasil. E-mail: adrianaufsm@gmail.com.br

${ }^{3}$ Mestrado em Ciência da Computação - Pontifícia Universidade Católica do Rio Grande do Sul (PUCRS) Pontifícia Universidade Católica do Rio Grande do Sul (PUCRS) - Porto Alegre, RS - Brasil. Professor do Ensino Básico Técnico e Tecnólogo - Instituto Federal de Educação, Ciência e Tecnologia Farroupilha (IFFAR)

- Alegrete, RS - Brasil. E-mail: mroza@iffarroupilha.edu.br
}

Submetido em: 06/02/2018 - Aceito em: 23/06/2018

(C) ETD- Educação Temática Digital Campinas, SP $\quad$ v.21 n.1 $\quad$ p.202-221 jan./mar. 2019 
current scenario and the understanding of blended learning. The paper continues with the construction of a synthesis of research on blended. Learning in both secondary school and in higher education. As a result, the research reveals a growing scenario of studies and experiments with blended learning that have their origin in individual teacher initiatives that enhance 21 st century student learning.

KEYWORDS: Learning Methods. Literature Review. Higher Education. High School.

\section{RESUMEN}

Blended Learning es un programa de educación formal que combina el aprendizaje presencial y en línea en coexistencia, valorando los diferentes modos de interacción, colaboración, participación y promoviendo la integración de las tecnologías digitales en la práctica pedagógica del educador. En este artículo, con el objetivo de explorar cómo esta temática se presenta en el escenario educativo brasileño, analizamos las disertaciones y tesis nacionales relacionadas a Blended Learning, en el período de 2013 a 2017, disponibles en la Comissão de Aperfeiçoamento de Pessoal de Nível Superior y en el Instituto Brasileiro de Informação em Ciência e Tecnologia. Así, partimos de una revisión sistemática de la literatura de esas producciones destacando el escenario actual y las comprensiones en torno al asunto, y seguimos con la construcción de una síntesis de las investigaciones dirigidas a la Educación Superior y la Enseñanza Media. Como resultado, las investigaciones nos revelan un escenario creciente de estudios y experimentaciones con Blended Learning, elaboradas generalmente a partir de iniciativas individuales de profesores, con la intención de potenciar el aprendizaje de los estudiantes del siglo XXI.

PALAVRAS CLAVE: Métodos de Aprendizaje. Revisión de la Literatura. Educación Superior. Enseñanza Media.

\section{INTRODUÇÃO}

Dentre as possibilidades educacionais que têm se destacado como uma inovação pedagógica, está o Blended Learning $(B L)$, ou Ensino Híbrido $(E H)$, nomenclatura utilizada com maior frequência no Brasil. O BL propõe a convergência entre práticas pedagógicas voltadas à educação presencial e práticas pedagógicas relacionadas à educação a distância (EAD), preferencialmente de modo simultâneo, com aporte das Tecnologias Digitais de Informação e Comunicação (TDIC) e de metodologias ativas. Nesse sentido, a concepção de $B L$ se baseia em uma ideia de educação híbrida - mista -, que mescla múltiplas práticas, espaços, indivíduos, tecnologias e culturas de maneira a potencializar a construção do conhecimento.

Desse modo, o $B L$ preconiza a valorização dos espaços presenciais, como a sala de aula, por exemplo, ao considerar que boa parte do processo de ensino/aprendizagem, das experiências e das vivências dos estudantes se constrói no ambiente presencial. Ao mesmo tempo, sugere que o enriquecimento dessas interações pode acontecer no universo virtual, ampliando globalmente os espaços educacionais.

Nesse sentido, a partir das concepções de Graham (2006) e de Christensen, Horn e Staker (2013), o BL é reconhecido como um modelo formal e inovador de educação que busca: potencializar a aprendizagem por meio da tecnologia; equilibrar a aprendizagem individual com a coletiva; integrar os espaços físicos com os virtuais; atribuir um papel mais interativo ao professor e mais autônomo aos estudantes; personalizar a aprendizagem (ao permitir que atenda ao ritmo e estilo de aprendizado dos estudantes); flexibilizar tempos e espaços, entre outros objetivos. 
No entanto, segundo Graham (2006), uma pergunta frequente, quando se fala em $B L$, é: "O que está sendo misturado?". Embora existam respostas heterogêneas a essa questão, as definições trazem poucas variações conceituais e, de forma geral, sinalizam como característica primordial a combinação da aprendizagem presencial com a on-line. Sendo assim, o potencial do $B L$ vem sendo construído em torno do nível de interação e de integração dessa aprendizagem e na transformação dos papéis assumidos pelos professores e estudantes. Nesse contexto, o ensinar/aprender é uma interconexão dinâmica, em que os papéis de educador e de educando podem ser vividos tanto pelo professor quanto pelos estudantes, em um processo de mediação recíproca.

Nessa perspectiva, ao assumirmos, como professores, o contínuo processo de aprendizagem da docência (que implica modos de aprender e fazer-se professor), entrelaçada a esta a aprendizagem da docência digital (DA ROCHA; BOLZAN, 2015), que exige ser professor em um cenário de cultura digital e de inteligência coletiva, conforme Lévy $(1999,2001)$, poderemos configurar novas concepções aos processos de ensinar e de aprender, por meio de espaços presenciais e/ou virtuais e de modelos/estratégias pedagógicas que permitam a integração efetiva das TDIC na educação, dentre estes o $B L$.

Se, na cultura contemporânea, crianças e adolescentes estão desenvolvendo novas habilidades e aprimorando suas capacidades de criatividade, de resolver problemas, de respeitar regras, de trabalhar em grupo, de ser autônomo, de aprender a partir de desafios que estimulam a colaboração, o encantamento e o envolvimento, sendo as tecnologias digitais meios que potencializam essas capacidades, também os saberes mobilizados na aprendizagem da docência precisam integrar um conhecimento tecnológico para saber "como", "quando", "o que" e "por que" ensinar com as tecnologias.

Por isso, as TDIC, em contextos de $B L$, constituem mais um desafio aos professores que estão buscando integrá-las aos processos de ensino/aprendizagem, uma vez que utilizálas para o seu próprio aprendizado difere de usá-las para o aprendizado com os outros. Assim, buscamos, neste artigo, apresentar o cenário atual das pesquisas educacionais relacionadas a $B L$, a fim de compreender de que maneira os professores estão apropriando-se desse conceito e explorando esse modelo.

Assim, apresentamos uma Revisão Sistemática da Literatura (RSL) que busca refletir o estado do conhecimento em torno das produções científicas no âmbito nacional, especificamente das teses e dissertações envolvendo estudos e experiências com $B L$. A nossa intenção é observar o movimento das pesquisas sobre essa temática, como se caracterizam, que estudos/experiências têm sido construídos, a fim de incentivar a integração das TDIC nos espaços educacionais contemporâneos a partir da perspectiva do $B L$. 


\section{BLENDED LEARNING: DEFINIÇÕES EM UM HORIZONTE DE POSSIBILIDADES}

Não há uma definição única e universal a respeito de $B L$. A sua concepção tem evoluído com o tempo, com as tecnologias, com as necessidades atuais e com as compreensões dos pesquisadores.

Driscoll (2002) apresentou quatro conceitos que se referiam a $B L$ : a) para combinar/misturar tecnologias baseadas na web; b) para combinar/misturar teorias e métodos de ensino/aprendizagem; c) para combinar tecnologias educacionais com aprendizagem dirigida por tutor/instrutor presencial; d) para integrar as tecnologias educacionais/corporativas com atividades de trabalho reais - esse último mais ligado ao contexto corporativo, onde é possível encontrar um bom número de "misturas" transformadoras. Essas definições serviram para demonstrar o potencial ainda inexplorado do $B L$ e para dizer que ele significava coisas distintas para diferentes pessoas.

Porém, Graham (2006) disse que, ao definirmos o BL de forma ampla, praticamente todos os sistemas de aprendizagem o contemplariam e não obteríamos a essência do que é $B L$, bem como porque ele tem se tornado atraente para a docência. Segundo o mesmo autor, o $B L$ deve refletir a ideia de combinação de dois modelos historicamente separados de ensino/aprendizagem: o tradicional, com sistemas de aprendizagem $F 2 F$ (da expressão em inglês face-to-face, em português face a face), e o modelo a distância, com os sistemas de aprendizagem distribuídos - Ambientes Virtuais de Aprendizagem (AVA), plataformas adaptativas, gamificação (que utiliza elementos de jogos para atingir determinados objetivos). Ou seja, é na intersecção dos dois modelos que o $B L$ vai emergir.

Essa compreensão, cada vez mais empregada, tem se tornado possível devido às constantes inovações tecnológicas, que possibilitam interações síncronas a partir de sistemas computacionais distribuídos e/ou dispositivos móveis, ao desenvolvimento natural das necessidades contemporâneas em torno da mistura de abordagens/metodologias educacionais e à auto(trans)formação de professores (DA ROCHA; BOLZAN, 2015) que buscam promover a aprendizagem dos estudantes no século XXI.

Nesse horizonte, Garrison e Vaughan (2008) definem BL como a integração orgânica de abordagens e tecnologias on-line cuidadosamente selecionadas e complementares. A expressão "orgânica" deve ser entendida como fundamentada na prática, enquanto que a expressão "cuidadosamente" suscita um repensar significativo da forma como devemos abordar as experiências de aprendizagem.

Os pesquisadores Christensen, Horn e Staker (2013) trazem um olhar avançado sobre a concepção de $B L$, definindo-o como um programa de educação formal no qual um aluno aprende, pelo menos em parte, por meio do ensino on-line, com algum elemento de controle do estudante sobre o tempo, lugar, modo e/ou ritmo do aprendizado e, ao menos em parte, em uma localidade física supervisionada fora de sua residência. Sendo que as atividades

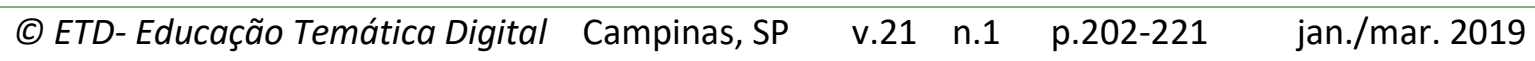


(lições em pequenos grupos, com mediação ou tutoria), ao longo do caminho de aprendizado de cada estudante, em um curso ou disciplina, são conectadas para oferecer uma experiência de educação integrada.

Além disso, Christensen, Horn e Staker (2013), apoiados por Moran (2015), enfatizam que o $B L$ deve integrar algumas dimensões, tais como: ênfase no projeto de vida dos estudantes - valorizando a construção de um projeto de vida que promova a convergência entre os interesses e paixões de cada aluno e seus talentos, suas histórias e seu contexto; ênfase em valores e competências amplas, de conhecimento e socioemocionais - para aprender a conhecer, a conviver, a ser e a agir -; ênfase no equilíbrio entre a aprendizagem personalizada e a compartilhada - considerando que podemos aprender por meio de múltiplas formas de colaboração, em diversos grupos, e/ou percorrer roteiros em graus diferenciados de aprendizagem. Desse modo, a definição de $B L$ evoluiu para abarcar um conjunto mais rico de estratégias e dimensões de aprendizagem (BACICH; NETO; TREVISANI, 2015).

Assim, no equilíbrio entre compartilhar (aprendizagem em equipe) e personalizar (aprendizagem individual), busca-se respeitar o ritmo e estilo de aprendizagem de cada estudante. Esse é um ponto favorável à integração das TDIC, pois os AVA, as plataformas adaptativas, os games, a Internet e seus infindáveis recursos permitem explorar o aprendizado de conteúdos em diferentes maneiras e formatos (texto, áudio, vídeo, games), respondendo, assim, ao interesse e aos modos diversificados de aprender, que são próprios de cada um ou de cada grupo, bem como criando oportunidades de maior engajamento entre os estudantes e destes com os professores.

Essas definições nos permitiram identificar tanto a maneira como o $B L$ tem sido pensado, bem como os pesquisadores que tem se destacado na literatura quando o tema é $B L$. Desse modo, predominam as produções de Graham (2006), Graham, Woodfield e Harrison (2013), Garrison e Kanuda (2004), voltadas ao BL na Educação Superior, mais especificamente à adoção e implementação institucional; as de Garrison e Vaughan (2013) e MacDonald (2008), também voltadas à Educação Superior; de Christensen, Horn e Staker (2013), direcionadas à Educação Básica (ou K-124); e de Sharma (2010), mais voltadas à pesquisa nos ambientes corporativos.

Esse horizonte nos mostra que o $B L$ não é um conceito estático e absoluto, mas híbrido, assim como sua própria concepção, na qual as TDIC, ao evoluírem, vão reconfigurando as possibilidades educacionais devido à riqueza de interações, de recursos e de experiências que elas nos permitem explorar.

\footnotetext{
${ }^{4}$ Expressão utilizada para se referir ao sistema educacional primário e secundário americano, em partes de Austrália e Canadá, equivalente a Educação Básica no Brasil.
}

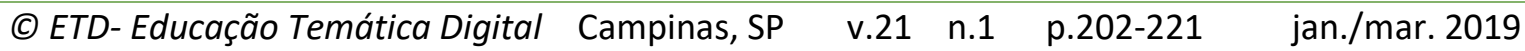




\section{CAMINHO METODOLÓGICO PARA O ESTADO DO CONHECIMENTO}

Neste artigo, analisamos as produções científicas relacionadas à temática do $B L$, publicadas nos últimos cinco anos, com vistas a amadurecer o conhecimento sobre o modelo. Desse modo, buscamos explorar como o BL está sendo introduzido no cenário educacional brasileiro e que contribuições e potencialidades do $B L$ vêm sendo apresentadas/destacadas.

Entendemos que realizar o levantamento das produções recentes é de fundamental importância para o desenvolvimento de novas produções científicas, nos permitindo "lapidálas" ao nos confrontarmos com diferentes enfoques, perspectivas, bases teóricometodológicas, resultados a serem considerados dentro de um determinado contexto. Além disso, poderemos identificar possíveis lacunas existentes que possam servir de estímulo a novas revelações e configurações de pesquisa.

Nessa direção, de acordo com Morosini e Fernandes (2014), entendemos o Estado de Conhecimento como identificação, registro, categorização, que levam à reflexão e síntese sobre a produção científica de uma determinada área, em um determinado espaço de tempo, congregando publicações relevantes sobre uma temática específica. Cabe ressaltar que realizar um Estado de Conhecimento em tempos de Internet, bibliotecas digitais e de pesquisa full-text pode parecer algo simples e descomplicado, se compararmos com algumas décadas atrás, em que boa parte do trabalho de busca era realizado manualmente. Contudo, ao considerarmos os novos tempos e o fluxo imenso de informações que se originam a cada milésimo de segundo na Web, a partir de fontes inesgotáveis, iremos perceber o quanto esse dilúvio é extremamente complexo, exigindo do pesquisador um olhar aguçado e disciplinado na seleção e recuperação daquilo que é ou não credível e relevante para a nossa revisão, pois, com muita facilidade, nos "desviamos" ou nos "perdemos" do objetivo principal nesse imenso mar, onde os links, ao "brilharem", nos convidam a um clique.

Diante dessas considerações, partimos em busca de estudos que pudessem ser significativos, atuais e representativos do movimento da pesquisa em torno da nossa temática. Assim, seguimos os passos da Revisão Sistemática de Literatura (RSL), encontrada em Depaepe, Verschaffel e Kelchtermans (2013) e Campbell (2017), para compor um híbrido entre mapeamento, avaliação e síntese, tecido a partir de interconexões do Estado de Conhecimento com a RSL. Nesse sentido, entendemos que a RSL está ancorada em uma estrutura na qual se dimensionam claramente os procedimentos específicos da revisão. E, embora a RSL não seja um tipo de revisão tradicional na área da Educação, ela começa a emergir como uma possibilidade ao considerarmos o contexto de cultura digital.

Segundo Vosgerau e Romanowski (2014), em sintonia com o estudo de RSL apresentada por Depaepe, Verschaffel e Kelchtermans (2013), é possível destacar seis recortes principais que orientam a análise de uma publicação e que podem ser aplicados generalizadamente em qualquer RSL: (1) as definições do conceito investigado apresentado

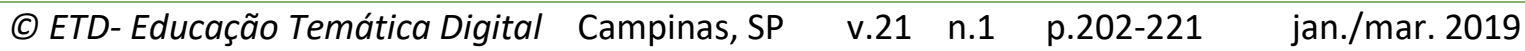


nos estudos; (2) a(s) questão(ões) de pesquisa; (3) o método de pesquisa empregado; (4) o país onde o estudo foi realizado; (5) o número e a origem dos participantes; (6) os principais resultados da pesquisa. E é a partir desses aspectos que nos orientamos para compor uma RSL.

\subsection{Achados de pesquisa em âmbito nacional}

Considerando a temática do $B L$, os achados de pesquisa são oriundos de produções científicas na área da Educação, porém não exclusivamente, devido à transversalidade do $B L$ em contextos de ensino/aprendizagem. O levantamento foi conduzido no Catálogo de Teses e Dissertações da Comissão de Aperfeiçoamento de Pessoal de Nível Superior (CAPES), inserido na Plataforma SUCUPIRA e na Biblioteca Digital Brasileira de Teses e Dissertações (BDTD) do Instituto Brasileiro de Informação em Ciência e Tecnologia (IBICT), e teve como intuito identificar e analisar as dissertações e teses desenvolvidas em âmbito nacional, referentes ao período de 2013 a 2017. Optamos por esse recorte temporal em razão das discussões em torno do tema serem recentes no campo da Educação, no cenário nacional, e das discussões/resultados envolvendo a integração das TDIC na Educação estarem em constante metamorfose.

Dentre as questões de pesquisa que norteiam essa investigação, estão: De que modo o $B L$ vem propagando-se na educação brasileira? Que estudos/experiências estão sendo desenvolvidos? Como os professores estão apropriando-se desse modelo educacional? Quais características do $B L$ estão sendo destacadas?

Assim, começamos o levantamento no catálogo da CAPES utilizando a palavra-chave "Ensino Híbrido" no termo de busca, colocando-a entre aspas com vistas a efetuar a pesquisa pela ocorrência exata. Conforme mencionado anteriormente, o termo Ensino Híbrido tem sido utilizado como tradução para $B L$ no Brasil, sendo, por isso, indispensável sua utilização na pesquisa. A busca foi realizada de setembro a novembro de 2017.

Nesse catálogo, inicialmente, retornaram 27 trabalhos. A partir disso, refinamos a busca, estabelecendo os anos de 2013 a 2017, para apresentação dos resultados, considerando como representativo o período dos últimos cinco anos para as teses e dissertações apreciadas, para o qual retornaram, então, 24 trabalhos. Considerando que a terminologia original, em inglês, é usada com frequência na literatura nacional, realizamos uma nova busca utilizando como palavra-chave "Blended Learning" (também entre aspas), para a qual retornaram 72 trabalhos, sendo 49 destes referentes ao período de 2013 a 2017.

Para o total de trabalhos encontrados no período de inclusão estabelecido (na busca por Ensino Híbrido e, logo depois, Blended Learning), foram identificadas 9 coincidências nas ocorrências. Dessa maneira, foram identificados 64 trabalhos diferentes nesse catálogo, para os quais consideramos como critério de inclusão a presença do termo de busca no título, no resumo e/ou nas palavras-chave das teses e dissertações.

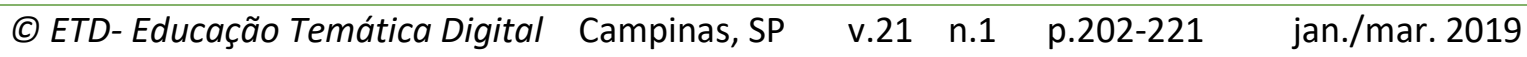


Partimos então, para uma busca na BDTD do IBICT que, assim como o catálogo da CAPES, abriga e dissemina as teses e dissertações defendidas, nas instituições brasileiras de ensino e pesquisa. Devido à sua estrutura de organização e dos filtros disponibilizados para a busca, realizamos diferentes combinações, de forma a localizar as produções relevantes: Blended Learning (no título, depois em assunto), Ensino Híbrido (no título, depois em assunto). Após a exclusão dos coincidentes, ficaram 28 trabalhos, dos quais 15 já faziam parte do levantamento no catálogo da CAPES, e outros 3 foram descartados, após leitura do resumo, pois não se relacionavam à temática. Desse modo, ficamos com 10 trabalhos a serem somados aos 64 da CAPES. O Gráfico 1 sintetiza as buscas efetuadas.

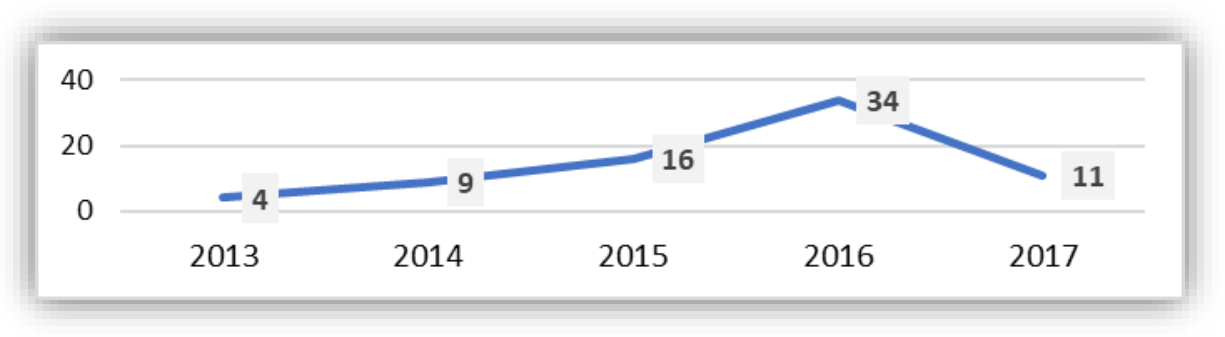

Gráfico 1 - Crescimento das pesquisas com Blended Learning no Brasil Fonte: Os autores (2017).

Além disso, identificamos a distribuição das produções em relação ao tipo de cursos de pós-graduação (Gráfico 2), para a qual notamos um número expressivo de dissertações advindas de cursos de mestrado profissional, sendo 16 produções (das 19) somente no ano de 2016.

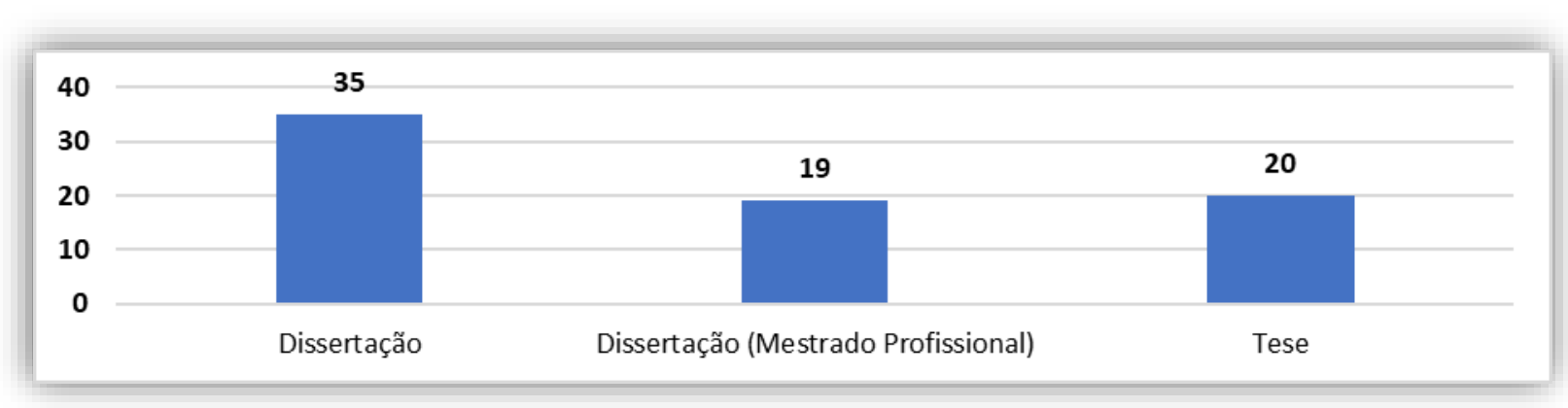

Gráfico 2 - As produções por curso de pós-graduação relacionadas a Blended Learning (2013 a 2017) Fonte: Os autores (2017).

Se considerássemos somente as produções registradas como sendo da área de conhecimento da Educação ou do Ensino, o refinamento, ainda que possivelmente adequado, não contemplaria as múltiplas experiências interdisciplinares que vêm sendo desenvolvidas com BL, limitando nosso olhar a no máximo 24 trabalhos (dos 74). Porém, as pesquisas sob a ótica do $B L$ realizadas no Brasil se propagam por diferentes áreas de conhecimento $\mathrm{e}$ programas de pós-graduação, contudo estão interligadas ao contexto da educação.

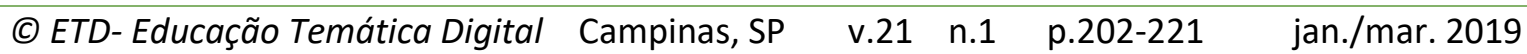




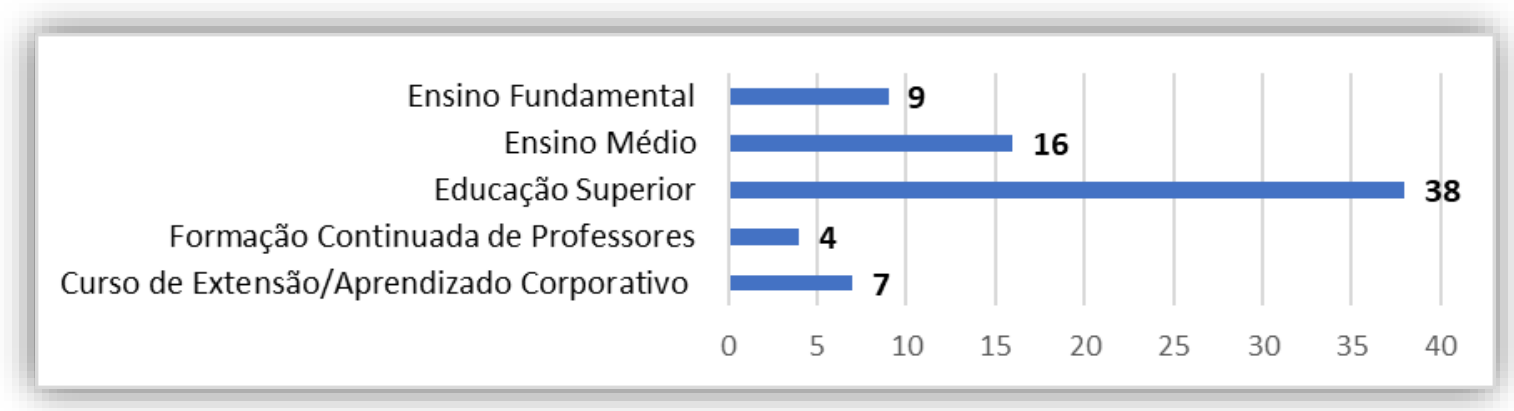

Gráfico 3 - Número de estudos com Blended Learning no Brasil (2013 a 2017)

Fonte: Os autores (2017).

Desse modo, consideramos necessária a leitura dos resumos dos 74 trabalhos previamente selecionados. De forma geral, esse conjunto de produções nos revelou que os estudos que citam $B L$, no Brasil, se concentram na Educação Superior, conforme mostrado no Gráfico 3.

\subsection{Análise do corpus: o Blended Learning em pesquisas}

A partir das produções científicas reunidas, construímos uma síntese das teses e dissertações direcionadas ao Ensino Superior e ao Ensino Médio (regular e técnico). Cabe ressaltar que, embora tenhamos adotado a expressão $B L$ no artigo, manteremos, na síntese, as expressões conforme mencionadas pelos autores, em sua obra. Cada produção foi revisada para determinar que o $B L$ foi estudado, e não simplesmente mencionado. Desse modo, a síntese apresentada reúne teses e dissertações que descrevem características relacionadas a $B L$, em experiências práticas.

A tese de Silva (2017) buscou investigar as contribuições da união entre Blended Learning e Inteligência Coletiva para a aprendizagem individual e coletiva. A pesquisa de caráter qualitativo foi desdobrada em levantamento bibliográfico e análise de dados provenientes de um curso blended, no âmbito da formação judiciária. O aporte teórico sobre BL é amparado em Horn e Staker (2015), com ênfase na alternância e integração entre a modalidade on-line e presencial. A personalização, uma característica destacada em Horn e Staker (2015), também foi considerada, permitindo aos alunos selecionar os conteúdos que melhor atendessem as suas necessidades de aprendizagem, por meio de vídeos, textos, discussões assíncronas, bem como de intervenções pontuais feitas pelo professor, a fim de esclarecer pontos específicos dos conteúdos.

Os sujeitos da pesquisa foram os 13 alunos (12 servidores e 1 magistrado) do curso "Cultura Digital: Trabalho, Tecnologias, Cognição e Aprendizagem", idealizado e realizado pelo autor da tese, em um período de 4 semanas, nas quais foram oportunizadas atividades colaborativas em ambiente on-line (MOODLE) e presencial, na Escola Judicial do Tribunal Regional do Trabalho da Segunda Região (EJUDE2) de São Paulo. De acordo com a análise dos dados gerados, provenientes de observação, informações e históricos gerados pelo AVA, e de

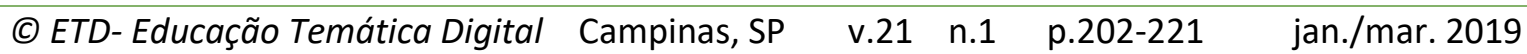


um questionário semiestruturado, aplicado aos participantes ao término do curso, foi possível encontrar evidências de que o $B L$, em sinergia com o que o autor definiu como operadores da Inteligência Coletiva em um AVA (o design instrucional, as mídias de função pós-massiva, a interatividade e a comunidade virtual de aprendizagem), favoreceu a emergência dessa inteligência e contribuiu para a aprendizagem tanto em nível individual quanto coletivo dos envolvidos. Assim, de acordo com os resultados, o autor propõe o $B L$ baseado na Inteligência Coletiva (BLBIC) como forma de favorecer a aprendizagem, por meio da criação de espaços virtuais ou presenciais mais ricos em colaboração, reflexão e autorregulação do aprendizado.

A tese de Pino (2017) teve como objetivo identificar e analisar propostas pedagógicas e tendências para a estruturação de cursos de graduação ofertados na modalidade de Educação a Distância (EAD), tendo como objeto de estudo 2 cursos de graduação, 1 público e 1 particular, para os quais foram estudadas suas respectivas metodologias e estratégias pedagógicas, bem como identificados os recursos digitais (AVA, objetos de aprendizagem, gamificação) presentes nos cursos. Os dados foram coletados através da observação e verificação in loco nas plataformas educacionais das instituições, dos planos de curso, documentos institucionais e materiais disponibilizados por uma disciplina, com equivalência, em cada um dos cursos. Além disso, foram realizadas entrevistas com diferentes atores envolvidos nesse processo de ensino/aprendizagem, tais como estudantes, professorestutores, coordenadores, diretores, com a finalidade de coletar dados para uma análise. A entrevista com os estudantes (183) teve como propósito coletar dados sobre o seu perfil, sua opinião sobre o AVA e sobre os conteúdos disponibilizados, desempenho dos tutores e preferências sobre ferramentas digitais.

O BL é parte da revisão da literatura da autora ao identificá-lo, de forma descritiva e exploratória, como uma das tendências no cenário da EAD. Assim, a concepção de $B L$ é apresentada a partir de Moran (2015), Macdonald (2008), Tori (2009) e seus modelos, brevemente descritos, na visão de Horn e Staker (2015). Em suas conclusões, Pino (2017) destaca que as estratégias da educação presencial estão sendo modificadas pela EAD, a fim de atender as demandas dos estudantes nativos digitais, e que não há uma metodologia própria e exclusiva destinada à educação a distância, sendo essas metodologias compartilhadas atualmente com a modalidade presencial, direcionando a educação para um formato blended apoiado pelas tecnologias, favorecendo o desenvolvimento de uma postura ativa e colaborativa dos estudantes.

A tese de D'Andrea (2016) também é direcionada ao ensino de língua estrangeira para fins específicos (LINFE), na qual investiga o processo de ensino/aprendizagem colaborativo, mediado pelas TDIC, em uma perspectiva êmica, valorizando as percepções, crenças e emoções dos aprendizes. Nesse sentido, a autora propôs desenvolver tarefas colaborativas como uma metodologia para o ensino de leitura em língua inglesa, em um contexto de sala de aula presencial mediado pelas tecnologias, partindo de princípios socioculturais em uma

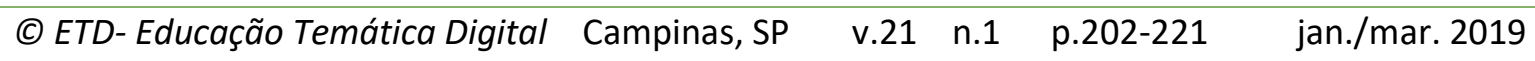


modalidade $B L$. O propósito foi entender como a aprendizagem se desenvolve a partir do ponto de vista dos estudantes.

Nas tarefas colaborativas (entendidas como atividades pedagógicas que requerem resolução de problemas, realizada de forma colaborativa), o BL é definido a partir de Sharma (2010), que o constitui como uma mistura ideal entre o ensino tradicional e o virtual, da mesma forma que em outros autores, como Graham (2006) e Tori (2009). A autora adotou uma metodologia de caráter qualitativo constituída como uma pesquisa-ação, envolvendo tarefas colaborativas em duplas e grupos, com alunos das disciplinas de Língua Inglesa Instrumental para os cursos de Engenharias e de Geologia, ambos presenciais, em uma universidade privada no sul do Brasil. No total, 15 alunos participaram da pesquisa em quatro encontros durante um semestre. Desse modo, a produção de dados foi feita através de entrevistas semiestruturadas, antes e após a aplicação das tarefas, e da análise das gravações das interações (em áudio e vídeo) dos participantes na realização dessas. As tecnologias digitais utilizadas foram o Padlet (que permite criar murais digitais colaborativos) e o site Schoology (um sistema de gestão de aprendizagem utilizado para criar, gerenciar e compartilhar conteúdo e recursos eletrônicos).

De acordo com os resultados obtidos, as tarefas propostas geraram colaboração entre os participantes, o que foi corroborado pelo reforço das crenças e da preponderância da interação e do papel dos colegas no aprendizado da língua inglesa. Em relação ao uso das tecnologias digitais, estas foram consideradas como geradoras de interesse por parte de alguns alunos. Porém, a autora concluiu que a abordagem blended não teve o impacto que ela previa, principalmente em se tratando das percepções dos alunos sobre as tecnologias que foram pouco afetadas pela proposta. Assim, as tecnologias influenciaram a realização das tarefas sob o aspecto da colaboração nas aulas, porém os alunos não se sentiram motivados a realizá-las em outros momentos. Para a autora, a perspectiva blended precisa ser criada como uma nova crença.

A tese de Souza (2015) teve como objetivo investigar as implicações da Aprendizagem Baseada em Problemas e Organizada em Projetos, em um ambiente de educação que combina atividades a distância e presencial ( $B L$, assim entendido pelo autor). $\mathrm{O}$ autor utilizou o termo em inglês Project Organized and Problem Based Learning, a partir de sua sigla $(P O P B L)$, na composição do modelo proposto. De acordo com o autor, o modelo é o encontro de uma modalidade inovadora $(B L)$ com uma metodologia ativa e não convencional ( $P O P B L)$.

Para atender a esse objetivo, Souza (2015) desenvolveu um estudo de caráter qualitativo por meio de uma pesquisa-intervenção, na qual analisou os fenômenos que ocorreram com a implantação da abordagem Blended Online POPBL como estratégia de ensino/aprendizagem, em uma disciplina de Introdução à Computação, no primeiro ano de um curso de Licenciatura em Química. Os participantes da pesquisa foram os 44 alunos (de 17 a 22 anos de idade) e o professor da disciplina, ofertada na modalidade $B L$ e apoiada no

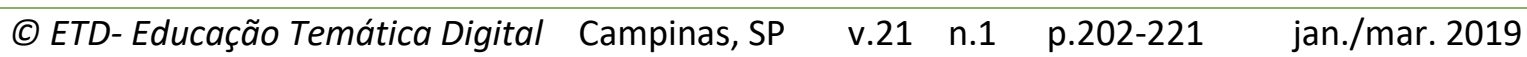


paradigma do POPBL. As atividades envolveram interações em um AVA e em outros ambientes on-line (redes sociais, e-mail pessoal) e encontros $F 2 F$, os quais ocorreram simultaneamente com as interações on-line.

A revisão bibliográfica sobre $B L$ é apoiado em Graham (2006). Para Souza, existem diferentes definições para o termo $B L$, sendo este descrito como uma combinação entre ambientes de aprendizagem presencial e ambientes virtuais de aprendizagem, com o objetivo de utilizar os pontos fortes de ambos. A análise dos dados, obtidos através de observação participante, questionários on-line e documentos on-line desenvolvidos pelos estudantes, ofereceu indicadores pedagógicos (implicações para o aluno e para o professor no processo formal de educação) e estruturais (espaços físicos e virtuais, recursos gráficos e de comunicação), evidenciando que a abordagem Blended Online POPBL mostrou-se eficiente como uma alternativa metodológica que escapa da massificação da educação totalmente presencial, uma vez que permitiu a construção de conhecimentos e a promoção de habilidades e atitudes, no tocante à aprendizagem e ao uso das tecnologias na prática do futuro professor.

Em sua conclusão, o autor destaca que implantar uma abordagem dessa natureza, parcialmente em uma única disciplina, sem a colaboração por parte do corpo docente do curso ou da gestão institucional, é uma tarefa extremamente desgastante para o professor do POPBL, pois, além de ter que lidar com o aspecto de inovação da própria abordagem e com a aceitação dos novos papéis de aluno e professor, o docente ainda deverá lidar com a confusão psicológica que poderá ocorrer entre esses papéis, ao alternar entre a metodologia tradicional e as experiências em uma abordagem nos moldes do Blended Online POPBL.

Na tese de Czepula (2015), foi analisado se a implantação de uma metodologia ativa, em um modelo de educação semipresencial, no processo ensino/aprendizagem aplicado aos estudantes das disciplinas de Atenção Farmacêutica I e II do curso de Graduação em Farmácia da UFPR, melhoraria a aprendizagem entre os alunos. O estudo, de caráter misto, foi dividido em três momentos: I) identificação dos estilos de aprendizagem dos alunos do curso de Graduação em Farmácia da UFPR; II) desenvolvimento e avaliação de um modelo de educação semipresencial; e III) estudo qualitativo com os docentes do curso de Farmácia da UFPR. No momento II, as disciplinas foram estruturadas combinando atividades de aprendizagem F2F com atividades desenvolvidas a distância, considerando: o contexto das disciplinas, o AVA, os objetivos de aprendizagem e a adequação pedagógica.

A definição de EH se deu a partir de Garrison e Kanuka (2004), Graham (2006), Tori (2009) e dos modelos apresentados por Horn e Staker (2015). O modelo de Ensino Híbrido utilizado nessa fase foi o virtual enriquecido, caraterizado por uma disciplina em que os alunos têm sessões de aprendizagem presencial obrigatórias com o docente, ficando livres para completar o trabalho restante distante do professor.

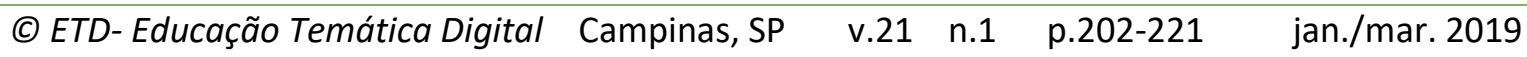


Nas conclusões apresentadas por Czepula (2015) em relação ao momento I, o estilo pragmático é o estilo de aprendizagem predominante entre os 297 alunos (correspondendo aos $58,3 \%$ dos matriculados) que participaram do questionário. Para avaliar a percepção e a satisfação dos alunos em relação à metodologia de ensino semipresencial utilizada e ao AVA, foi usado um questionário on-line baseado no BL Toolkit (2011). Dessa forma, no desenvolvimento e avaliação do modelo aplicado, momento II, obtiveram-se resultados positivos em relação ao desempenho dos alunos na aquisição de conhecimentos ao longo das disciplinas, por meio da realização e comparação dos resultados entre avaliações diagnóstica (pré-teste realizado no primeiro dia de aula) e somativa (pós-testes), baseadas na Taxonomia de Bloom. Participaram desse momento os estudantes matriculados nas disciplinas de Atenção Farmacêutica I e II, que, voluntariamente, responderam os questionários disponibilizados.

Referente ao momento III, um estudo qualitativo com os docentes do curso complementou a avaliação anterior, uma vez que, com a realização de entrevistas, buscou-se avaliar seu conhecimento em relação ao modelo de EAD aplicado, bem como sua percepção e aceitação. Os professores, apesar do pouco conhecimento e pouca experiência em EAD, demonstraram uma excelente aceitação, bem como acreditam ser uma tendência para os cursos de graduação. A maior parte dos docentes respondeu que trabalharia com as suas disciplinas nesse modelo. Em síntese, com a implantação dessa metodologia, foi avaliada a melhora da aprendizagem dos alunos em resposta à problemática da pesquisa.

No Quadro 1, sintetizamos as dissertações relacionadas a $B L$, a partir dos objetivos/questões de pesquisa apresentadas. 


\section{QUADRO 1. Objetivos de pesquisa das dissertações}

1a $\quad$ Pereira (2017) teve como objetivo formular e avaliar uma proposta didática utilizando EH no AVA Edmodo, com o intuito de contribuir com o processo de ensino/aprendizagem de Química dos estudantes de um curso técnico, em um Instituto Federal de Educação, e verificar o grau de satisfação dos estudantes e do professor em relação ao modelo híbrido e ao AVA.

2a $\quad$ Ostolin (2017) buscou analisar a influência do $B L$ nos processos de ensino, aprendizagem e avaliação na disciplina de Cinesiologia do curso de graduação em Fisioterapia. Foram analisados os dados de histórico de acesso e participação dos estudantes em atividades disponíveis no AVA, os dados de desempenho acadêmico e os dados de participação do monitor da disciplina.

3á $\quad$ Severo (2017) parte de um contexto de BL em que se experimentou o uso do WhatsApp para a promoção de diálogos espontâneos entre aprendizes de Inglês como Língua Estrangeira. Dentro de uma perspectiva sociocultural que considera que a aprendizagem se dá através da mediação de artefatos socioculturais e na interação com outros sujeitos, a autora buscou compreender como se dá a mediação da aprendizagem através de uma ferramenta comunicacional amplamente utilizada na atualidade.

4a Saldanha (2017) relata uma proposta de ensino de língua inglesa com auxílio da língua musical, aliada à tecnologia mobile, para a realização de um videoclipe. A atividade envolveu a criação de um videoclipe de uma música, com turmas de 10 ano do Ensino Médio de 2 escolas, 1 pública e 1 particular, da cidade de São Paulo. O desafio desse trabalho foi demonstrar que o uso da tecnologia em sala de aula está muito mais acessível do que se pensa, uma vez que os próprios celulares dos alunos foram utilizados como coadjuvantes no processo de ensino/aprendizagem, destacando as vantagens do trabalho em grupo.

5a $\quad$ Cacavallo (2016) buscou identificar e analisar termos que evidenciassem as inovações presentes na prática do EH no Brasil, partindo da perspectiva da Teoria Ator-Rede (ator: pessoa, um objeto, uma instituição; rede: nós onde os atores estão conectados), através de entrevistas com 6 representantes de instituições que pesquisam e aplicam o EH no Brasil.

6a $\quad$ Schmitz (2016) teve como objetivo contribuir para a inovação dos processos de ensino/aprendizagem utilizados pelos docentes da Universidade Federal de Santa Maria, por meio da disponibilização de material didático instrucional sobre sala de aula invertida e metodologias ativas de aprendizagem, apresentado no formato de vídeo e arquivos de texto.

7ạ $\quad$ Silva (2016) teve como finalidade investigar se a implementação de atividades baseadas no EH contribui para a qualificação do ensino/aprendizagem de História. Para isso, o autor organizou atividades seguindo o modelo de sala de aula invertida e rotação por estações, para um grupo de estudantes de uma turma do Ensino Médio.

8a $\quad$ Santos (2015) buscou investigar os elementos necessários ao processo de organização didática do EH nos cursos de licenciatura presenciais do Instituto Federal do Maranhão (IFMA), levando em consideração os documentos institucionais e a infraestrutura administrativa, tecnológica e pedagógica. $O$ estudo mostrou que a implementação da carga horária em EAD exige o planejamento de ações em diferentes perspectivas; e que o EH é uma alternativa para o cumprimento da carga horária dos cursos, com melhor aproveitamento para o desenvolvimento do currículo e diversificação das estratégias didáticas, visando à qualidade do ensino.

9a Borba (2014) analisou um modelo pedagógico definido como "Sala de Aula Conectada", através das percepções docente e discente na disciplina de Arte na Educação dos cursos presencial e a distância de Pedagogia, ambos da Universidade de Brasília (UnB). O modelo de "Sala de Aula Conectada" tem como base a interligação de duas ou mais salas, fisicamente distantes, por meio da videoconferência via Internet, conduzida por um professor com o apoio de tutores, sendo essas salas de aula presencial da Faculdade de Educação da UnB, as quais se ligaram a dois polos presenciais da UAB/UnB para a realização de trabalhos colaborativos, formados por grupos on-line.

Fonte: Os autores (2018). 


\section{RESULTADOS E DISCUSSÕES}

Ao empreendermos uma análise da produção científica brasileira, a partir das teses e dissertações encontradas no Catálogo de Teses e Dissertações da CAPES e na BDTD do IBICT, percebemos que a concepção de $B L$ está fortemente ligada à noção de educação a distância, sendo, muitas vezes, entendida e simplificada como uma experiência de ensino semipresencial, delimitando, assim, o potencial do $B L$ a ser explorado.

Percebemos, através da RSL, que $43(58,1 \%)$ do total (74) das produções localizadas envolveram experiências com a utilização de uma tecnologia digital em sala de aula, tais como: o celular (SALDANHA, 2017); um AVA (SILVA, 2017), (PINO, 2017), (PEREIRA, 2017), (OSTOLIN, 2017), (SOUZA, 2015); o Whatsapp (SEVERO, 2017); a web (SCHMITZ, 2016), um objeto digital de aprendizagem (D'ANDREA, 2016), citando, assim, o uso de $B L$, sem necessariamente aprofundar-se no contexto de $B L$, salvo os 14 trabalhos sintetizados que, além de atenderem os critérios anteriormente citados, trazem mais do que apenas a alusão a $B L$.

Do total de produções sistematizadas, 14 (18,9\%) exploraram o estudo ou a aplicação de uma metodologia ativa, como encontrado em Souza (2015), ou um modelo de BL, tais como: a sala de aula invertida - encontrado em Pereira (2017), Silva (2016) e Schmitz (2016); o modelo de rotação por estações - também em Silva (2016) e na interpretação de Saldanha (2017); ou o modelo virtual enriquecido - encontrado em Czepula (2015), 12 (16,2\%) produções se propuseram a investigar práticas/tendências pedagógicas da modalidade a distância ou semipresencial, utilizando a expressão $B L$ como sinônimo, como visto em Pino (2017), Santos (2015) e Borba (2014), inovações em modelos de Ensino Híbrido, como em Cacavallo (2016); 5 (6,7\%) produções acabaram sendo desconsideradas. Algumas discussões teóricas em torno da efetividade do $B L$ também fazem parte do cenário nacional atual.

Em termos de sistema educacional (Gráfico 3), verificamos que a Educação Superior $(38,51 \%)$ é o contexto da maioria das produções que citam o $B L$, reiterado pelas produções que foram sintetizadas, em que 9 destes 14 trabalhos concentraram suas experiências em cursos de graduação, dentre esses: Silva (2017), Ostolin (2017), Severo (2017), D’Andrea (2016), Souza (2015), Czepula (2015). No âmbito do Ensino Médio, embora o número de produções seja mais discreto (16, correspondendo a 21\%), estas vêm intensificando-se com experiências oriundas de diferentes instituições de ensino, públicas e privadas, como visto em Saldanha (2017) e Silva (2016), e dos Institutos Federais de Educação Ciência e Tecnologia, como em Pereira (2017), que concentram a oferta de Cursos Técnicos de Nível Médio no país e onde os saberes e práticas contemporâneas precisam articular-se, em sintonia, com o mundo do trabalho. Já, as produções relacionadas a $B L$ na Educação Básica (9, correspondendo a 12\%) são mais recentes, concentrando-se nos anos de 2016 e 2017, voltadas para os anos finais do Ensino Fundamental.

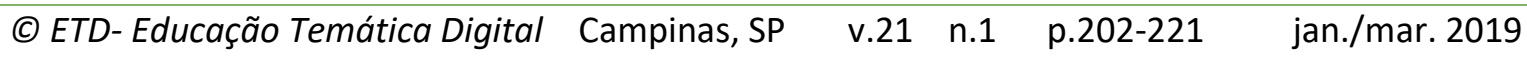


Em relação aos sujeitos da pesquisa, os estudantes são o foco da maioria (63, correspondendo a 81\%), refletido em 9 das 14 sínteses apresentadas, sendo que somente 5 $(6,7 \%)$ do total (74) de produções se dedicaram à formação continuada de profissionais, professores ou tutores, como encontrada em Silva (2017), Cacavallo (2016) e Schmitz (2016). Algumas produções, como de Pino (2017), Czepula (2015) e Borba (2014), buscaram atingir diferentes atores do processo de ensino/aprendizagem.

Quanto à metodologia empregada, predomina a pesquisa qualitativa de cunho exploratório e relatos de experiência oriundos de estudo de caso, pesquisa-ação, observaçãoparticipante e não-participante, pesquisa-intervenção e algumas de caráter misto, corroborado pelos 14 estudos sintetizados. Essas pesquisas enfatizam o uso de questionário e/ou entrevistas na produção dos dados, porém nem todos os estudos explicitam a forma de análise de dados, salvo alguns que anunciam a Análise do Discurso como (Pereira, 2017) e (Ostolin, 2017) ou a Análise de Conteúdo encontrada em (Cacavallo, 2016) e (Santos, 2015).

Em relação ao aporte teórico sobre $B L$ nas produções sumarizadas, aparecem com frequência: Christensen, Horn e Staker (2013), Horn e Staker (2015), Graham (2006), seguidos por outros autores, tais como: Macdonald (2008), Sharma (2010), Garrison e Kanuka (2004). Alguns autores nacionais também são citados, como Bacich, Neto e Trevisani (2015), Tori (2009), Moran (2015).

Para Graham (2006), o BL pode ser estruturado em quatro níveis diferentes: nível de atividade, nível de curso, nível de programa, nível institucional. Cada nível pode ser implementado de acordo com o contexto específico e as restrições reais. A partir da construção da RSL, descobrimos que, no Brasil, as produções acadêmicas têm explorado, com frequência, configurações de $B L$ em nível de atividade em cursos ofertados na modalidade presencial. Algumas iniciativas em nível de curso são apresentadas por Pino (2017) e Santos (2015).

\section{CONSIDERAÇÕES FINAIS}

Entendemos que o $B L$ é uma abordagem/estratégia pedagógica inovadora, que está desenvolvendo-se e reconfigurando-se pelos avanços tecnológicos e digitais, como aconteceu com a EAD, a qual se transformou e se expandiu para atender as novas demandas educacionais. $O$ diferencial é que o $B L$ não exclui uma modalidade educacional em prol de outra, pelo contrário, propõe que utilizemos mais e melhor o potencial disponível em cada modalidade, para que a aprendizagem significativa aconteça através de práticas efetivas.

Nesse sentido, o $B L$ é o meio termo ou, sendo bem otimista, um ponto de equilíbrio, nem só presencial nem só a distância. Com isso, o $B L$ se difere do conceito de semipresencial, pois a intenção maior é de que a combinação possa ocorrer simultaneamente, colaborativamente e de forma personalizada, ou seja, em aula blended o professor pode e precisa fortalecer as misturas de interações ( $F 2 F$ e presencial), integrar diferentes

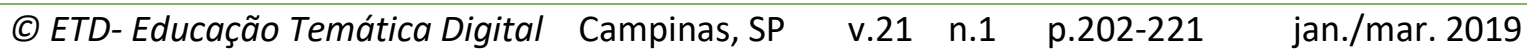


metodologias e estratégias de aprendizagem, harmonizar o individual e o coletivo, qualificar o uso das tecnologias digitais em sintonia com o contexto sociocultural que se está desenvolvendo - o de cultura de convergência digital.

Considerando que, no Brasil, a modalidade de ensino semipresencial oferece parte da carga horária presencial e outra parte a distância, os cursos superiores presenciais, amparados pela portaria 4.059/2004 do MEC, podem ministrar até $20 \%$ da carga horária total do curso no formato semipresencial. Nesse sentido, alguns professores, ao utilizarem parte da disciplina, que é presencial, a distância, entendem que estão utilizando $B L$. O que, de todo, não está incorreto se pensarmos nas primeiras definições - mais amplas, como as apresentadas por Driscoll (2002).

Porém, a concepção de $B L$ evoluiu e se reconfigurou de tal maneira que passou a ser entendida como a integração entre: sistemas de aprendizagem distribuídos (AVA, plataformas adaptativas, gamificação, dispositivos móveis, e outras TDIC); aprendizagem compartilhada (em conjunto e colaborativa) e personalizada (reconhecendo e valorizando o estilo de aprendizagem dos estudantes, o conhecimento prévio, o contexto); metodologias ativas (sala de aula invertida, aprendizagem baseada em problemas, instrução em pares) e dimensões pessoais (trajetória e projeto de vida, cultura, valores e competências socioemocionais).

Desse modo, é preciso entender que o $B L$ é mais do que simplesmente alternar entre modelos/estratégias/tecnologias/culturas/tempos da educação presencial e da distância, ainda que isso também seja necessário. É preciso integrar tudo isso de uma maneira mais efetiva, em que o mix não seja a exceção, mas pensado que, dentro de um contexto específico, diferentes modos de ensino/aprendizagem sejam reconhecidos, incentivados e praticados pelos professores, conectando: "o que ensinar?" com o "como ensinar?" e o "a quem ensinar?".

Para concluir, evidenciamos um número crescente de professores experimentando o $B L$, fruto de iniciativas individuais, no entendimento de que é essencial um olhar para os diversos modos de ensinar/aprender, misturando estratégias on-line e tradicionais em harmonia, ampliando e aprofundando a integração das TDIC para colaborar com a prática, a experimentação, a colaboração, o desenvolvimento da autonomia, da proatividade, e, nessa direção, conquistar 0 envolvimento dos estudantes com 0 seu processo de ensino/aprendizagem. A atitude dos professores em criar situações de $B L$ é significativa e elogiável. Porém, ao considerarmos que diferentes saberes pedagógicos e tecnológicos precisam ser mobilizados, é na interação e na prática colaborativa, entre pares, que tornaremos mais acessível o $B L$ na educação. 


\section{REFERÊNCIAS}

BACICH, Lilian; NETO, Adolfo Tanzi; TREVISANI, Fernando de Mello. Ensino híbrido: personalização e tecnologia na educação. Porto Alegre, RS: Penso, 2015.

BORBA, Kalina Ligia de Almeida. Educação a distância na Sala de Aula Conectada: a percepção discente e docente sobre uma experiência no curso de Pedagogia da Universidade de Brasília. 2014. 215 p. Dissertação (Mestrado em Educação) - Universidade de Brasília, Brasília. 2014.

CACAVALLO, Marcello. Inovações no ensino híbrido: a perspectiva da teoria ator-rede. 2016. 118 p. Dissertação (Mestrado em Comunicação) - Universidade Municipal de São Caetano do Sul (USCS), São Caetano do Sul, 2016.

CAMPBELL Collaboration. 2017. What is a systematic review? Disponível em: http://www.campbellcollaboration.org Acesso em: 29 de abril de 2017.

CZEPULA, Alexandra Ingrid dos Santos. Inserção de módulos semipresenciais no processo ensino-aprendizagem nas disciplinas de atenção farmacêutica no curso de graduação em farmácia na UFPR Curitiba, 2015. 268 p. Tese (Doutorado em Ciências Farmacêuticas) Universidade Federal do Paraná, Curitiba, 2015.

CHRISTENSEN, Clayton; HORN, Michael; STAKER, Heather. Ensino híbrido: uma inovação disruptiva? uma introdução à teoria dos híbridos. Maio 2013. 49 p. Disponível em: https://www.christenseninstitute.org/publications/ensino-hibrido Acesso em: 10 jan. 2016.

D’ANDREA, Letícia Pires. As emoções no processo de aprendizagem de língua inglesa: uma perspectiva sociocultural para o ensino de línguas para fins específicos. 2016. 235 p. Tese (Doutorado em Linguística Aplicada) - Universidade do Vale do Rio dos Sinos, São Leopoldo, 2016.

DA ROCHA, Adriana Moreira; BOLZAN, Doris Pires Vargas. La cultura de convergencia digital y la inclusión sociocultural: Interconectando formación y práctica docente. Educatio Siglo XXI, v. 33, n. 3, p. 123-146, 2015. Disponível em: http://revistas.um.es/educatio/article/view/240901 Acesso em: 28 jan. 2016.

DEPAEPE, Fien; VERSCHAFFEL, Lieven; KELCHTERMANS, Geert. Pedagogical content knowledge: a systematic review of the way in which the concept has pervaded mathematics educational research. Teaching and Teacher Education, v. 34, p. 12-25, 2013. Disponível em: http://www.sciencedirect.com/science/article/pii/S0742051X1300053X . Acesso em: 5 mar. 2017.

DRISCOLL, Margaret. Blended learning: Let's get beyond the hype. e-learning. IBM Global Services. Mar. 2002, 1.4: 1-4. Disponível em: https://www-07.ibm.com/services/pdf/blended learning.pdf . Acesso em: 4 jul. 2017. 
GRAHAM, Charles. Blended learning systems: definition, current trends, and future directions. In: BONK, Curtis; GRAHAM, Charles., eds. The handbook of blended learning: global perspectives, local designs. San Francisco: John Wiley \& Sons, 2006. Cap. 1, p.3-21. Disponível em: http://www.publicationshare.com/graham intro.pdf Acesso em: fev. 2017.

GARRISON, Randy; KANUKA, Heather. Blended learning: uncovering its transformative potential in higher education. Internet and Higher Education, v. 7, n. 2, p. 95-105, 2004.

GRAHAM, Charles; WOODFIELD, Wendy; HARRISON, Buckley. A framework for institutional adoption and implementation of blended learning in higher education. The internet and higher education, jul. 2013, v.18. p. 4-14. Disponível em: http://www.sciencedirect.com/science/article/pii/S1096751612000607 . Acesso em: 5. mar. 2017.

HORN, Michael. B.; STAKER, Heather. Blended: usando a inovação disruptiva para aprimorar a educação. 320 p. Porto Alegre: Penso, 2015.

LÉVY, Pierre. Cibercultura. São Paulo: Ed. 34, 1999.

LÉVY, Pierre. A inteligência coletiva: por uma antropologia do ciberespaço. 8.ed . São Paulo: Loyola, 2011.

MACDONALD, Janet. Blended learning and online tutoring: Planning learner support and activity design. Aldershot: Gower, 2008.

MORAN, José Manuel. Educação híbrida: um conceito-chave para a educação, hoje. In: BACICH, Lilian; NETO, Adolfo Tanzi; TREVISANI, Fernando de Mello. Ensino híbrido: personalização e tecnologia na educação. Penso Editora, 2015.

MOROSINI, Marília C.; FERNANDES, Cleoni M. B. Estado do Conhecimento: conceitos, finalidades e interlocuções. Educação Por Escrito, Porto Alegre, v. 5, n. 2, p. 154-164, jul./dez., 2014.

OSTOLIN, Thatiane Lopes Valentim Di Paschoale. Ensino Híbrido na Formação Profissional em Fisioterapia: Potencialidades, Desafios e Fragilidades, 2017. Dissertação. (Mestrado em Ciências da Saúde). Universidade Federal de São Paulo, Santos, 2017.

PEREIRA, Rafael Peixoto de Moraes. 0 uso de NTICs no ensino-aprendizagem de química no IFRN. 2017. 100 p. (Mestrado em Ensino). Universidade do Estado do Rio Grande do Norte, Pau dos Ferros, 2017.

PINO, Adriana Soeiro. Educação a Distância: propostas pedagógicas e tendências dos cursos de graduação. 2017. 167 p. Tese. (Doutorado em Educação) - Universidade Nove de Julho (UNINOVE), São Paulo 2017.

SALDANHA, Soraya Rozendo Vancini. O videoclipe e a linguagem mobile como estratégia do processo de ensino-aprendizagem de língua inglesa no ensino médio. 2017. 91 p. Dissertação (Mestrado em Letras) - Universidade Presbiteriana Mackenzie, São Paulo, 2017.

(C) ETD-Educação Temática Digital Campinas, SP $\quad$ v.21 n.1 $\quad$ p.202-221 jan./mar. 2019 
SANTOS, Simone Costa Andrade dos. Práticas pedagógicas da modalidade a distância e do ensino presencial: contribuições para Ensino Híbrido no Instituto Federal do Maranhão. 2015. 82 p. Dissertação (Mestrado em Ensino) Centro Universitário UNIVATES - Lajeado, 2015.

SHARMA, Pete. Blended learning. ELT journal, 2010, 64.4: 456-458.

SEVERO, Suzan Severo. O uso do Whatsapp como ferramenta para o desenvolvimento da habilidade comunicativa em inglês como língua estrangeira em um contexto de Blended Learning. 2017. 87 p. Dissertação. (Mestrado em Linguística Aplicada) - Universidade do Vale do Rio dos Sinos, São Leopoldo, 2017.

SCHMITZ, Elieser Xisto da Silva. Sala de aula invertida: uma abordagem para combinar metodologias ativas e engajar alunos no processo de ensino-aprendizagem. 2016. 185 p. Dissertação (Mestrado Profissional em Tecnologias Educacionais em Rede) - Universidade Federal de Santa Maria, Santa Maria, 2016.

SILVA, Jorge Everaldo Pittan da. Ensino híbrido: possíveis contribuições para a qualificação do ensino de História no Ensino Médio. 2016. 67 p. Dissertação (Mestrado Profissional em Ensino de História) - Universidade Federal de Santa Maria, Santa Maria, 2016.

SILVA, José Erigleidson da. Blended learning baseado na inteligência coletiva - BLBIC: análise de um curso de formação judiciária. 2017. 245 p. Tese (Doutorado em Educação, Arte e História da Cultura) - Universidade Presbiteriana Mackenzie, São Paulo, 2017.

SOUSA, Sidinei de Oliveira. Blended online POPBL: uma abordagem Blended Learning para uma Aprendizagem Baseada em Problemas e Organizada em Projetos. 2015. 278 p. Tese (Doutorado em Educação) - Universidade Estadual Paulista Júlio de Mesquita Filho, São Paulo, 2015.

TORI, Romero. Cursos híbridos ou blended learning. In: LITTO, Fredric Michael; FORMIGA, Marcos. (Org.) Educação a distância: o estado da arte. p.121-128. São Paulo: Pearson Education do Brasil, 2009. 461 p.

VOSGERAU, Dilmeire Sant'Anna Ramos; ROMANOWSKI, Joana Paulin. Estudos de revisão: implicações conceituais e metodológicas. Revista Diálogo Educacional, Curitiba, v. 14, n. 41, p. 165-189, jan./abr. 2014. Disponível em:

http://www2.pucpr.br/reol/pb/index.php/dialogo?dd1=12623\&dd99=view\&dd98=pb . Acesso em: 2 fev. 2017.

Revisão gramatical do texto sob responsabilidade de: Grazielle S. Santos.

E-mail: graziesp@hotmail.com 